\title{
Role of GST in Indian Pharma Sector
}

\section{Mrinal SK and Rao J*}

Department of Pharmaceutical Chemistry, Bharati Vidyapeeth Deemed to be University, India

*Corresponding author: Janhavi Rao; Department of Pharmaceutical Chemistry,

Poona College of Pharmacy, Bharati Vidyapeeth Deemed to be University, Erandwane, Pune-411038, India, Email: janrao61@gmail.com

\section{Abstract}

Goods and Services Tax is one of the significant tax reforms which subsume 7-8 taxes that are applicable to the pharma sector. They include Value Added Tax, service tax, octoroi tax, Central Sales Tax, excise duty, custom duty, additional excise duty, etc. These multiple taxes are then categorised into three types that are State Goods and Service Tax, Central Goods and Service Tax and Integrated Goods and Service Tax. Goods and Services Tax affect the manufacturing by having different rates of tax for raw materials and for end product that is formulation. The effects of Goods and Services Tax with rates $0 \%, 5 \%$ and $12 \%$ on price are depending upon the category of the item or product or health care service. In this review we have tried to discuss role of GST that is positive as well as negative role on Indian pharma sector.

Keywords: Goods and Services Tax, Tax structure, SGST, CGST, IGST, Rates of GST, Lifesaving drugs, Health care services

Abbreviations: GST: Goods and Services Tax; VAT: Value Added Tax; CST: Central Sales Tax; SGST: State Goods and Services Tax; CGST: Central Goods and Services Tax; IGST: Integrated Goods and Services Tax; NLEM: National List of Essential Medicines; BCD: Basic Custom Duty; MRP: Maximum Retail Price; API: Active Pharmaceutical Ingredient.

\section{Introduction}

Goods and Service Tax (GST) is one of the biggest Tax reform in the era of Indian Indirect Taxation industry, which is the one hundred and twenty-second amendment passed as the Constitution's One Hundred and Twenty Second Amendment Act, 2017 that was implemented by the July 1st, 2017 throughout the country [1,2]. It subsumes 7-8 taxes like CST, VAT, excise duty, Service tax, and additional excise duty, Luxury Tax, Entertainment Tax and many more. GST is the single taxation system in India which helps in elimination time, cost and effort [1,35]. Under GST, goods and services are taxed at the rates of $0 \%, 5 \%, 12 \%, 18 \%, 28 \%$. Different sectors have both positive and negative effects on them including pharma sector [1,6,7]. GST replaced almost 17 federal and state taxes with one uniform tax and eliminated the trouble arising from multiple taxes $[2,8]$.

India is one of the largest countries in terms of production of generics and the country's pharmaceutical industry is now the third largest in the world in concern of volume and ranks, fourteenth in concern of value. The Indian health care sector is expected to touch 150 billion dollars by the end of year 2017 observing an increase of 70 billion dollar from 2012. For rationalizing the tax structure and optimizing the distribution there is 


\section{Open Access Journal of Pharmaceutical Research}

reduction in the cost of production and distribution which is helping the industry to pass the benefits to the buyer. Presently the country's GDP expenditure on health care sector is about $5 \%$. Hence by passing the GST bill the focus of all industries has been hooked $[3,8]$. Purpose of this review is to focus the role of GST on Indian pharma sector with its pit falls.

\section{Current Tax Structure}

Following are the indirect taxes which are either eliminated or combined to form the GST

1. VAT

2. Taxes applicable on lotteries

3. Service Tax

4. Purchase Tax

5. Octroi Duty

6. Luxury Tax

7. Food Tax

8. Entry Tax

9. Entertainment Tax

10. Commercial Tax

11. CST

12. Central Excise Duty

\section{Advertisement taxes [1]}

From above, only some taxes are applicable to pharma sector those are combined to form GST are listed below 1. VAT- Which is levied on sale of goods within the state at an approximate rate of $5 \%, 12.50 \%$ and $14.50 \%$.

2. Service tax- Which is levied on services at an approximate rate of $15 \%$.

3. Octoroi duty/ entry tax - Which is levied on goods within state or local limits.

4. CST- Which is levied on inter-state of goods at an approximate rate of $2 \%$ if goods are for resale else at VAT rate.

5. Excise duty-Which is levied on manufacture of goods at an approximate rate of $12.50 \%$.

6. Customs duty - which is levied on import of goods at an approximate rate of $29.44 \%$ [9,10].

\section{Salient Features of GST}

It is affirmed that multiple indirect taxes are categorized into a dual structure GST levy with two component of tax that are $[1,9,10]$ (Figure 1 ).

\section{Components of tax}

\section{Intra- state sales}

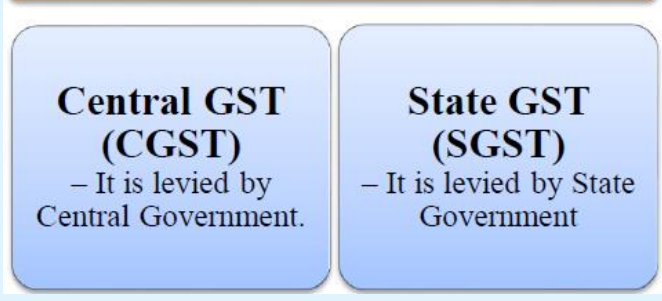

Figure 1: Dual structure GST levy with two component of tax.

\section{Impact of GST on Different Areas in Pharma Sector}

Impact on manufacturing: In the manufacturing of products the effect of GST on raw material and end product that is formulation is different. There are two main things that have changed; they are manufacturing price- many raw materials for API and products have moved from 5\% VAT bracket to 12\% GST bracket and a lot of medicine salts/compounds have moved from $5 \%$ to
$12 \%$ GST bracket. As the raw material cost has gone up by $7 \%$ the pharmaceutical companies have to pay more in manufacturing cost and hence the MRP of the product need to be changed to absorb that impact [11].

Impact on different formulation: For the formulations like tablets, capsules, liquids, etc used in the allopathic medical care and other health related items falls in three categories that are GST at $0 \%, 5 \%$ and $12 \%$. Human 


\section{Open Access Journal of Pharmaceutical Research}

blood, its components, all types of contraceptives as well as some life-saving drugs have no GST on them. But under current indirect taxation the life-saving drugs and some health care services are exempted from the Excise duty and Custom duty and 5\% taxes are charged on medicines in some states $[1,5,6,12]$. For most of the medicines the GST on their formulations is $12 \%$ as compared to the earlier $9.5 \%$ effective rate that is VAT + Excise duty. There are also some medicines like Oral Rehydration Salts, insulin had no excise duty but now have 5\% GST $[1,4,5]$.

Impact on price: Prices of medicines with $12 \%$ GST have been increased by about $2.30 \%$ in post GST implementation but the prices of medicines with 5\% GST will have no change from before. This is the scenario in the state like Gujarat but in few states, VAT and excise duty are at different rate on certain items. If VAT and excise duty were both at zero then the increase post GST will be $0 \%, 5 \%$ and $12 \%$ depending on which category the item is now. If excise duty was at the usual rate of $6 \%$ and VAT was zero, the increase in MRP post-GST will be 0.90 $\%$ or $7.6 \%$, depending on whether the item is now in the $5 \%$ or $12 \%$ GST slab.

The ceiling prices of medicines listed in the NLEM have been increased by the government. There is $2.3 \%$ augmentation in the ceiling prices of price controlled drugs that is for NLEM drugs in 12\% GST category. Incidentally less than $12 \%$ of domestic pharma market of more than Rs 11 lakh crore is covered by price control of NLEM drugs. As per the Drug Price Control Order, 2013 the drugs which are not under price control are allowed a $10 \%$ price increase every April. Due to GST for these drugs not under price control, the government did not allow the $2.3 \%$ price increase and has asked drug companies to maintain the same MRP from July 1, too. . Pharma companies have been allowed to put a sticker on medicines which are made before July 1, 2017 for NLEM 2015 drugs. For medicines which are made after July 1 , 2017, the new revised MRP for NLEM 2015 drugs is to be printed on the label reflecting the $2.3 \%$ increase.

GST is applied on the transaction cost that is price charged at every stage. So, the GST is charged by the manufacturer, wholesaler and distributor on their sale price and not on MRP [1].

Impact on Consumer: The GST rate on a commodity has been fixed such that the incidence due to the new rate is approximately equal to the earlier tax incidence due to VAT and excise duty. VAT was $5 \%$ and excise duty where applicable - was $6 \%$ of $65 \%$ of the MRP. The MRP included the VAT and excise duty. No seller can sell at more than the MRP.

It doesn't make any positive difference to the consumer if the GST is included on APIs which are raw material. APIs mostly fall in the category of $18 \%$ GST matching the effective VAT plus excise duty incidence of $17.6 \%$ before the GST regime. Particular APIs fall under the 5\% GST category and the formulations falls under the $5 \%$ or $12 \%$ category.

Let's understand how GST is applicable with an example, as a formulation manufacturer if someone buy API at Rs 1000 say plus 180 i.e. with $18 \%$ GST rate, but if he sell the formulation made from the API at Rs 2000then he collect from his buyer Rs 240 i.e. with GST rate $12 \%$ in addition. He transfer to the government Rs. 240; 180 through API manufacturer on paying his bill of Rs. 1180 and 60 directly to the government. As before, all GST paid to the government is collected from the end consumer or patient: nobody in the chain from API manufacturer or dealer to formulations manufacturer-dealer-retailer really pays out of his/her pocket in the final analysis [1].

\section{Impact on transport}

The GST affects the transport in following manner for different conditions:

1. Intra State - For sales within the state

Applicable taxes: CGST, SGST

2. Inter State - For sales from state A to state B

Applicable tax: IGST

3. Import in India from outside India

Applicable taxes: IGST, Basic Customs Duty (BCD)

4. Stock transfer - From a warehouse in state A to another warehouse in State B

Applicable tax: IGST [9]

\section{Overall Impact of GST on Pharma Sector}

\section{Positive Impact}

Eliminate the cascading effect of multiple taxes: As 8 different types of taxes were imposed on the Pharmaceutical Industry when GST was not into practice but now all those taxes were converted into one uniform structure that is GST [1,2,4-7].

Reduction in manufacturing cost and cost of technology: Now a days the machinery and equipment required for production are imported and thus, are very costly. The duty levied on these machinery and equipment is not allowed as a tax credit under the current tax system. While under GST, duty charged on such import would be allowed as a credit [1,4-7]. 


\section{Open Access Journal of Pharmaceutical Research}

Better prospects of medical tourism in country: GST is helping Medical Tourism industry in an indirect way. India currently enjoys a competitive advantage over developed countries as the cost of healthcare in India is about 30-40 percent of the similar medical treatment and procedures in those countries. The cost of healthcare package including insurance, pharmaceuticals, and international travel is expected to reduce with GST $[1,3,4,6]$.

Inverted duty structure: Existence of an inverted duty structure in pharma sector is observed currently. As the raw materials are costlier in terms of duty rather than finished products, so it adversely affects the domestic manufacturer. There is either disposal of this structure or bringing in a refund of the accumulated credit is proposed, under GST. For pharmaceutical sector this would be of a great benefit $[1,6,9]$.

Encouragement of alternative medicine system: Alternative medicine practices in India like Ayurveda, Yoga, Unani, Siddha, Homeopathy and Acupuncture are more popular amongst foreigners apart from the drugs and medicines. These alternative medicine practices give India an important edge over most of its competitors such as Malaysia, UAE, South Korea, Thailand and Singapore. It is forecasted that GST would encourage this sector and also efficiently contribute towards the growth of medical tourism in the country $[1,6]$.

\section{Negative Impact}

Medicines that are taxed currently at 5\% attracting $12 \%$ tax once GST came into effect. There is still an equivocalness in the prices of life-saving drugs and healthcare services. Now a days these are freed from the Excise and Customs Duties, but there is still an uncertainty about this after GST because most of them fall under the $5 \%$ GST $[4,6]$.

The indirect tax paid by pharma companies is augmented by $60 \%$ and MRP by $4 \%$ because of GST. Hence leaving a tax rate of $15 \%$ which is said to be $18 \%$ for diagnostics and reagents.

Other pharma drugs, medicines, pharma products and medical technology products that are ranged between $5 \%$ or $12 \%$ with mostly being a total tax including VAT of $11.5 \%$ to $12.5 \%$ to $18 \%$ [1].

The pharma companies are relishing the area based exemptions by setting up their units in some specific locations that no longer exists; this increased cost will be burdening the end consumers. These are the factors that have to be arranged by the companies so that it doesn't affect the overall cost making it difficult for the users $[8,13]$.

Lot of Ayurvedic formulations are coming in the category of $12 \%$ to $15 \%$ as most of them are covering cosmetic range [14].

\section{Conclusion}

GST is one of the biggest transformations in the Indian tax industry. This is going to be a game changer for many pharmaceutical industries. As it is replacing almost 7-8 taxes which were applicable to the pharmaceutical industry in the one uniform tax, so it is eliminating the complexity of the multiple taxes. And these multiple indirect taxes are divided in to three categories as SGST, CGST and IGST. GST has it's positive as well as negative impact on different areas in pharmaceutical sector like manufacturing, formulation, price of product and service, transport, etc. GST implementation is results in an efficient supply chain. The inter-state transaction between two dealers has become neutral by replacing the Carrying and Forwarding distribution model. Most of the life- saving drugs, health care services and medicines now fall under the $5 \%$ category of tax and these are exempted from the increase in the tax. But the impact of GST is still not transparent. So, the impact of GST on pharma industry is intermediate and overall it's a win-win situation for pharma industry in concern of both consumers and industry players with decrease in complexities and overall reduction in cost it translates to be a profitability and will help in development hopefully.

\section{References}

1. Chetan Shinde CA (2017) Impact of GST on Pharmaceutical Industry. H\&R Block Blog.

2. What Will be The Impact of GST on Healthcare and Pharma Sector. Boiphar.

3. Impact of GST on Healthcare and Pharma Sector. Cleartax.

4. How GST Will Effect To Pharma Distributors?. Health Kind labs.

5. GST impact on Indian Pharmaceutical Sector. Deskera.

6. Impact of GST on Pharmaceutical Sector. intechsystems. 


\section{Open Access Journal of Pharmaceutical Research}

7. Impact Of GST On Pharma Companies. Web Hopers.

8. Ashish P (2017) Impact of GST on Pharma industry. ET Health world.

9. Suresh Nair (2016) India's looming Goods and Services Tax (GST): considerations for the pharmaceutical industry. EYGM Limited, India

10. Neha B, Naresh M (2017 ) Goods and Services Tax (GST) in Indian Pharmaceutical and Its impact on industry. Pharmatutor 5(8): 7-11.
11. Sameer B (2017) Impact of GST on Pharmaceutical Industry. ET Health world.

12. https://veedacr.com/impact-of-gst-onpharmaceutical-industry/

13. Manish P, Rakesh G, Arun R (2016) GST impact on Business Strategy of Pharmaceutical Companies. Bio Spectrum pp: 53-57.

14. Kinjal V, Parvaiz AP, Neelam S (2018) Impact of GST on Pharmaceuticals: An Overview. Open Access Journal of Pharmaceutical Research 2(2): 1-12. 